\title{
Preserving Special Collections through Internal Security
}

\section{Gregor Trinkaus-Randall}

\begin{abstract}
Manuscript librarians and archivists continually face the dual responsibility of preserving their collections and making them available to researchers. Carefully designed reading room rules and regulations can protect the manuscripts and increase researcher's respect for efforts to preserve historical records. This paper examines some of the policies and procedures that can be implemented to minimize the possibility of theft or of willful damage to manuscripts by researchers or staff.
\end{abstract}

Manuscripts and Archives [Sterling Memorial Library, Yale University] exists to preserve the heritage of the past and to make it available to scholars. Our regulations are not intended to hamper your research but to provide access to the collections in a manner which insures their careful preservation. We ask readers to consider our books and manuscripts, not as a means to a personal end, but rather as a permanent resource. ... ${ }^{1}$

"The end of all archival effort is to preserve valuable records and make them available for use. Everything an archivist does is concentrated on this dual objective. ${ }^{\prime 2}$

Library and archives security is an important yet often neglected aspect of the normal day-to-day operations of a repository. Although archivists are aware of the problem of theft from repositories and damage to manuscripts, many feel "it won't happen to me" or "if I ignore the problem maybe it will go away." Unfortunately neither statement is realistic. As Kenneth Duckett has emphasized, a curator's "first duty is to his manuscripts-to keep and preserve them. ${ }^{\prime \prime 3}$ By the same token, manuscripts serve no one if they are kept locked in a vault or inaccessible in stacks. Making manuscript collections available for research exposes them to the possibility of being mishandled, torn, put out of order, disfigured or stolen. Consequently, archivists face the dual responsibility of preserving their collections and yet providing access to them for research. If archivists accept this responsibility, they must minimize the chances of either theft of or damage to the materials. The principal method for reducing these possibilities is controlled or restricted access to the materials. This paper explains some steps that can be taken to address this dual responsibility.

While the physical security of a repository is crucial to the safety of collections, many security issues have more to do with policies and procedures than with the physical conditions of the building. ${ }^{4}$ Any security program needs to involve, or at least keep in mind, the staff, the patrons, and the collections. Keys to a program's success are staff involvement in its design and implementation and good planning. Soliciting input from the staff can avert or minimize hard feelings and objections because the employees will understand the reasons for the rules and regulations.

Certain questions about a repository's current operations are necessary to determine if a security program is needed. How many and which employees have master and/or vault keys? Are all these keys necessary for each area or should there be a key sign-out? Is there an employee super-

Gregor Trinkaus-Randall, formerly Librarian/Archivist at the Phillips Library, Peabody Museum of Salem, is Collection Management Consultant, Massachusetts Board of Library Commissioners, 648 Beacon St., Boston, Massachusets 02215. 
vising the reading room at all times? Do all chairs face the reference desk? Is the reference archivist situated in a place where he or she can easily observe all activity in the room and, if not, are there circular detection mirrors situated in the rear corners of the room? Is the staff familiar with the most efficient way to observe reading room activities? Do they tend to limit their observations to the center and bottom half of the room, or more appropriately do they divide the room into quadrants and systematically check each area? Do they know what to do if they witness someone stealing or mutilating a document? Has contact been made with the local police department to ensure close cooperation and a quick response if necessary?

\section{"' 'Staff have been held accountable for all but 25 percent of library thefts.' "'}

When working with or hiring staff, it is important to emphasize security issues and to determine, as much as possible, their feelings toward these issues. It has been recommended that background checks be instituted for selecting special collections staff and that employees be bonded under a theft insurance plan, ${ }^{5}$ especially since "staff have been held accountable for all but 25 percent of library thefts. ${ }^{\prime \prime}$ Staff consciousness of potential problems and willingness to enforce rules and regulations are crucial to the establishment of a well-rounded program. In addition, by ascertaining the employees' position on these issues, one can hope to minimize the possibility of an archivist being tempted to remove items either for his or her own collection or for sale. Unfortunately it has happened, for example, when a special collections librarian from Boston College was apprehended trying to sell rare books to Sotheby's auction house in New York.

Information on reading room procedures was requested from twenty-six repositories across the country to ascertain differences in regulations. Twenty responses were received, for a return rate of 77 percent (see figure 1).

Researchers are, after the staff, the next group to consider when developing security procedures. It is crucial that these regulations be applied uniformly to all. First, each patron should sign a registration card and read and sign the policy statement of the repository. This procedure alerts the uninitiated and shows that the repository cares about its manuscripts and expects patrons to do likewise. The policy statement also strengthens the archivist's position if the patron is seen ignoring the rules and regulations. The registration card should include spaces for name, address, company or institution (when applicable), and research topics. This information should be checked against some form of identification which some institutions retain until all materials have been returned to the reference desk at the end of the day.

Personal belongings, including outerwear, umbrellas, handbags, shoulderbags, knapsacks, bookbags, briefcases, typewriter cases, envelopes and attache cases, must be checked outside the reading room, in lockers, or at the reference desk. Only pencils, notepaper or index cards, typewriters (as long as they do not bother other researchers), cameras, personal computers (without printers) and other material germane to the research as determined by the archivist should be allowed in the reading room. Some institutions provide loose notepaper, some insist on notecards only, and some provide notepaper with one or more holes punched in it. This last precaution is so that when the reader exits, his notes can be examined for concealed manuscripts by inserting a rod through the hole and shaking, thus allowing loose manuscripts to fall out. If there are several holes in the paper, the space between them should be small enough so that no manuscripts can be hidden.

Once registered, patrons should be interviewed. As recently as the 1960 s, most researchers would write ahead to the archivist and upon their arrival would present a letter or introduction from their major professor or another appropriate 
RESULTS OF TIE SURVEY OF ARCIIIVAL READING ROOMS (20)

(The information tabulated below refers only to that which was written in the forms provided)

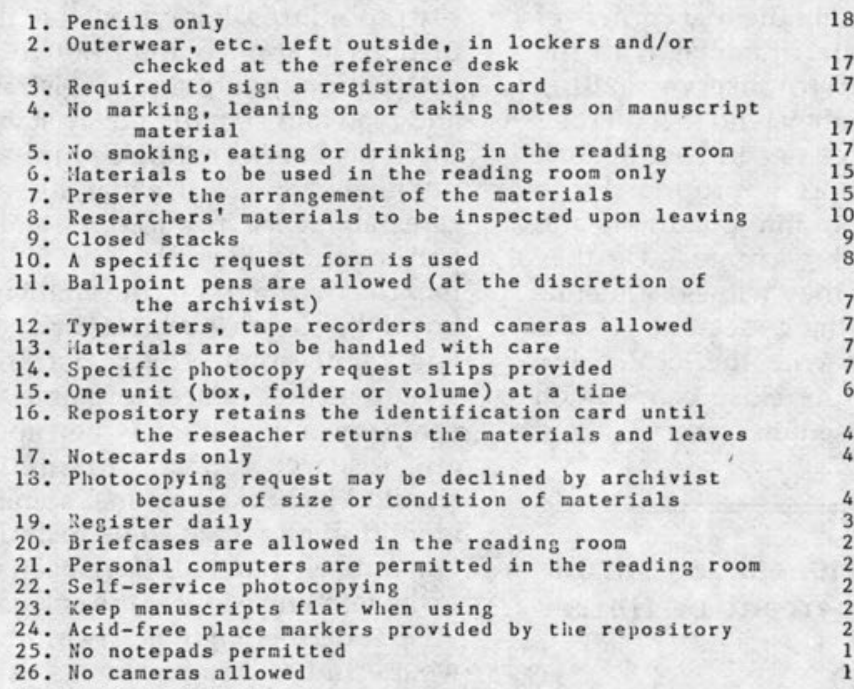

FIGURE 1

Results of the Survey on Archival Reading Rooms (20)

contact. Now this occurs only occasionally. Therefore, the initial interview serves as an introduction for both parties. The researcher can take advantage of the curator's knowledge of the collections and of other research in the field, and the archivist can learn about the researcher's topic. The curator should explain the repository's guides, finding aids, card catalogs, and services and introduce the reader to any other staff who might be of assistance. The interview should be informative, polite, clear, and helpful. The curator should assist and direct the patron based on the latter's research and not try to modify his or her topic. The interview should not be chatty. On the other hand, it is an art to conduct an efficient interview when readers want to talk at length about their research.

Some institutions specifically limit the amount of material a researcher can examine at one time. Often a large number of boxes or folders will be retrieved and retained at the reading room desk. If a box is permitted, usually only one folder is allowed to be open at a time. Everything must be examined while lying flat on the table and consistently handled with care. Not only is there less chance this way of a researcher tearing an object, but this procedure also allows the reference archivist's view of the reading room to remain unobstructed. It should be made clear to all researchers that no marks can be made on the manuscripts and that they must not lean, trace, or take notes on any material. The original order of all collections must be preserved. When finished with a folder, the reader should replace it in the box in its proper order. When research is completed on the materials in a box, it should be returned to the desk and another retrieved. No researcher should be allowed to work after hours unsupervised. All materials should be returned to the reference desk at the end of the day and checked by the archivist. If the reader has not completed his or her work on certain manuscripts, these may be placed on 
reserve until the next day. If the staff has retained a form of identification at the time of registration, they should return it after examining the returned materials.

Many institutions provide photocopying services for their patrons. Although some repositories allow self-service photocopying, most do it for their patrons, and restrictions usually apply. Archivists consistently retain the option to deny permission if the materials are too fragile or are too large for the machine. Also, several institutions limit copying only to certain hours, thus relieving the staff of numerous trips to the photocopy machine throughout the day.

Although a wide range of restrictions has been enumerated, patrons, particularly after the rules have been explained, are usually more than willing to cooperate. Occasionally a researcher will insist that something is out of place or in the wrong collection. At that point the archivist should be firm and calm. As mentioned earlier, all security procedures must be applied uniformly and enforced. If a patron is allowed to bully the archivist into relenting, then a precedent has been set regarding other patrons, and the collections may be in greater danger of mutilation or theft than before.

\section{"It is essential to compile an accurate inventory or register that, while not providing a description of every item, allows a document to be placed in context."}

There are numerous ideas concerning the safety of collections. One of the most helpful procedures in safeguarding collections is complete and accurate record keeping and the development of thorough finding aids. Complete accession and cataloging records that provide an accurate description of the provenance and the materials are crucial. As the items or collections are processed, it is essential to compile an accurate inventory or register that, while not providing a description of every item, allows a document to be placed in context. Item-level lists of citations (not complete descriptions) to particularly valuable items can be placed in appendixes to the register or in the archivist's control file (see figure 2). Unprocessed or partially processed collections, if accessible to researchers, may be good targets for theft.

Materials of significant monetary value can create a problem for the archivist. If there are few, some institutions photocopy them, put the photocopy in the collection, and shelve the original in its own folder in a vault or another safe place. This procedure has created problems for some archivists who believe that separating items destroys the concept of provenance for the collections.

Another way to safeguard these valuable items is to put each in its own folder that can be checked each time a box is given to and returned by a researcher. If, however, neither of these options is desirable or possible given the size of the collections, some archivists have found it preferable to microfilm the whole collection and make the microfilm available to the researchers. Often this last option is not viable, usually for financial or staffing reasons. Most often archivists will probably choose to take none of the above actions but will instead rely on the rules and regulations and observation of the researchers to protect the collections.

Marking collections has proved to be a deterrent to theft, and it is also good legal proof of ownership. On the other hand, it can disfigure and ruin the aesthetics of the document. Over the years there have been three main methods of marking documents: embossing, punching or perforating, and stamping with ink.

Embossing can result in partial obliteration of information. It is also a cumbersome, time-consuming procedure that can damage the paper fibers and, therefore, tends not to be very popular. Punching holes or perforating the document was once quite common but has since fallen completely from favor. Stamping with ink remains the final option. Both the $\mathrm{Na}$ tional Archives and the Library of Congress have used this method for many 


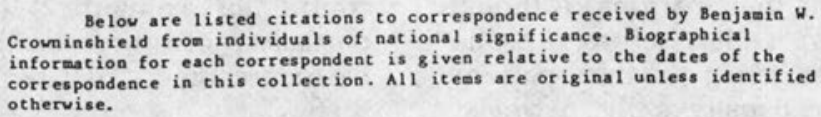

\section{FIGURE 2}

Appendix IV. Benjamin W. Crowinshield Non-Family Correspondence

years. Stamping, if used properly with visible or invisible ink, should result in minimal damage, especially since the recommended size of a stamp is only $5 / 8$ of an inch in diameter. The key is to use "an ink that is nonfading, ineradicable with solvents or bleaches, neutral or slightly alkaline in $\mathrm{pH}$, essentially nonbleeding and nonmigratory, stable at heat up to $300^{\circ} \mathrm{F}$, [resistant] to light for at least one hundred years, and slow drying on the stamp pad but fast drying on the document. ${ }^{17}$ Since such inks are not available commercially, the Preservation Office of the Library of Congress, in conjunction with the Government Printing Office, has developed one and offers it free of charge.

Among those institutions that do stamp their manuscripts, opinion varies as to where the stamp should be placed. In March 1982, the Rare Book and Manuscripts Section of the Association of College and Research Libraries published guidelines for marking rare books and manuscripts in College \& Research Libraries News as an appendix to "Guidelines for the Security of Rare Books, Manuscripts and Other Special Collections (Draft II). ${ }^{\prime 8}$ Some problems do exist with stamping, but they deal mostly with time, staffing and aesthetics. Most institutions do not have the staff or the time to stamp all the documents they own or even a significant part of them. For example, in 1966, "the archivist of the United States [James B. Rhoads] estimated that it would take five 
thousand man-years and cost twenty million dollars to mark the holdings of the National Archives."' Consequently, the decision to mark the collections, or part thereof, necessitates careful planning.

Librarians and archivists should be familiar with the laws that address thefts from repositories, especially since they often vary from state to state. For example, in Massachusetts thefts from private institutions are prosecuted under normal criminal law. However, Chapter 196 of the Acts of 1986 of the Commonwealth of Massachusetts amends the general law to make it a crime to conceal intentionally or to remove without authorization public records of any jurisdiction. It also states that if any custodian of public records thinks that a theft is being committed, he or she has the authority to detain the suspected thief until the police arrive, without being charged with false arrest. ${ }^{10}$ By comparison, the State of Virginia has passed an extensive law defining the penalties for "injuring or destroying books and other property of libraries" (Class I misdemeanor), for the "concealment of book or other property while on the premises of library; removal of book or other property from library" (larceny), for the "exemption from liability for arrest of suspected person," and for "failure to return book or other library property."

The Wisconsin law, based upon the Virginia one, added an additional feature: "The offense of library theft is graded, depending on the value of the materials taken: less than $\$ 500$ is a Class A misdemeanor; $\$ 500-\$ 2,500$ is a Class E felony; and more than $\$ 2,500$ is a Class $C$ felony." ${ }^{12}$ At the federal level, Public Law 771 of June 25, 1948, of the 80th Congress (Title 18 of the United States Code, Section 2071) states that "Whoever willfully and unlawfully conceals, removes, mutilates, obliterates, or destroys, or attempts to do so, or, with intent to do so takes and carries away any record, proceeding, map, book, paper, document, or other thing, filed or deposited with any clerk or officer of any court of the United States, or in any public office, or with any judicial or public officer of the United States, shall be fined not more than $\$ 2,000$ or imprisoned not more than three years, or both" and
"Whoever, having the custody of any such record, proceeding, map, book, document, paper, or other thing, willfully and unlawfully conceals, removes, mutilates, obliterates, falsifies, or destroys the same, shall be fined not more than $\$ 2,000$ or imprisoned not more than three years, or both." ${ }^{13}$

Thus far, the day-to-day operations of a repository and that institution's relation to its researchers have been discussed. Important security questions also arise in the event of a disaster or a fire alarm or drill in a repository. In the case of a fire alarm or drill, it is crucial that the archivists observe that no materials leave the reading room in a researcher's possession and that all researchers exit the building. There have been instances when patrons, because they felt that it was "just a fire drill," attempted to continue their research. This must not be permitted.

Normally, if a disaster occurs, no one is allowed inside the building until the fire marshall has inspected the facilities and determined that the structure is stable enough for people to enter. In such situations, the safety of people comes first. The institution's disaster plan should be reviewed with representatives of the local police and fire departments so that potential responses to emergencies can be planned and coordinated. The police will help keep outsiders away, but they may also bar staff from entering. Consequently, they should be familiar with key staff persons, and an identification or badge system should be implemented so that staff are not barred from the scene at a time when they can be most helpful. In fact, badge systems (staff identification) are always useful-not just in disaster situations. Maintaining adequate security during a disaster can be difficult. Everyone working on the recovery effort should be known to at least one person, staff preferably. Anyone who is unknown and cannot produce sufficient identification as part of the salvage team should be barred from the site.

Because the number of people working on recovery can get unwieldy, the choice of volunteers should be selective. Volunteers can be of great assistance if they are competent and willing to listen, but too 
many can make monitoring difficult, thus possibly compromising security. No one should attempt to restore anything on site, because such actions can result in the need for far more extensive and expensive restorative work later on.

The dual responsibility of maintaining and preserving manuscript and special collections and providing access to them requires considerable forethought and planning. Rules should facilitate research and assist in the protection and orderly administration of these materials. Librarians and researchers share the responsibility for preserving these rare, fragile, and unique materials. Any procedures should allow access to collections while also ensuring that they are maintained as permanent resources. Registering patrons, barring all but essential research materials (pencils and paper, typewriters and/or computers), imposing limits on the quantity of material available to a researcher at one time, and determining the ways in which it may be used are keys to the smooth and safe operation of a special collections repository.

In addition, care must be given to the records that document a department's manuscript and rare book holdings. The most complete accession, cataloging, and processing records possible enhance the identification and recovery of items that may be removed from the repository without authorization.

Additional measures may help reduce the possibility of theft: checking individual folders before and after a box of manuscripts is provided to a researcher, using identification methods such as embossing or stamping, and examining researchers' possessions as they leave.

Familiarity with state and federal laws regarding theft and/or mutilation of library materials will allow curators to address problems without overstepping the limits of the law. Finally, it is crucial, if and when a disaster occurs in a repository, that security measures already be in place and understood by the institution's staff and the police and fire departments. This preparation and precaution will avoid embarrassing and potentially dangerous situations at the scene and allow disaster recovery activities to proceed smoothly and safely.

The procedures described can usually be devised and promulgated inexpensively and frequently are more effective than sophisticated electronic systems. By implementing many of the procedures outlined in this paper, special collections librarians and manuscript and archives curators can greatly reduce the dangers to their collections through theft and mutilation.

\section{REFERENCES AND NOTES}

1. Manuscripts and Archives, Sterling Memorial Library, rules and regulations of the reading room.

2. T. R. Schellenberg, Modern Archives: Principles and Techniques (Chicago: Univ. of Chicago Pr., 1975), p. 224.

3. Kenneth W. Duckett, Modern Manuscripts: A Practical Manual for Their Management, Care, and Use (Nashville: American Assn. for State and Local History, 1975), p.220.

4. Richard W. Boss, "Collection Security," Library Trends 33:42-43 (Summer 1984).

5. Timothy Walsh, Archives and Manuscripts: Security (Chicago: Society of American Archivists, 1977), p.5.

6. Mary Wyly, "Special Collections Security: Problems, Trends, and Consciousness," Library Trends 36:251 (Summer 1987).

7. Walsh, Archives and Manuscripts: Security, p.9.

8. "Guidelines for the Security of Rare Books, Manuscripts and Other Special Collections (Draft II)," College \& Research Libraries News 43:90-93 (March 1982).

9. Ibid.

10. Commonwealth of Massachusetts, Acts and Resolves, 1986, Chapter 196, p.60-61.

11. Peter J. Parker, "Statutory Protection of Library Materials," Library Trends 33:86 (Summer 1984).

12. Ibid., p.87.

13. 18 United States Code Annotated, Section 2071. 